tincture of iodine were ordered to be used frequently; and in those cases in which a viscid mucus clogged the larynx, small doses of ipecacuanha were administered.

E. D-, aged twenty-three, a porter, had suffered from hoarseness for over three weeks, and from entire aphonia for a fortnight. He complained of no nain, but of an inability to clear the tinroat. The laryno ...... se showed general congestion of the larynx. The hospital preparationcompound squill mixture, with ten minims of ipecacuanha wine, was ordered three times a day. A blister was applied to the neck, and the larynx was brushed with the chloride of zinc. In a fortnight the voice had returned; but as he complained of loss of appetite and general debility, a tonic was ordered, and he remained under treatment for a fortnight longer.

M. S-, aged thirty-five, unmarried, had lost her voice for five weeks. She stated that when her voice first went she suffered from acute pain in the throat, but that latterly there had been no pain whatever. She complained of constant cough. With the laryngoscope the cords as well as the adjacent parts were seen to be deeply reddened. A creasote inhalation was ordered, and the compound ointment of iodine was applied to the neck. The larynx was brushed with the chloride of zinc. On the following week there was no improveinent whatever; a blister was therefore ordered to the neck; the application to the larynx was continued, and, as the patient complained of want of rest, Dover's powder was given at bedtime. At her next visit there was decided improvement in the voice; the treatment was continued. At the following visit her voice was very greatly improved, but the cough remained troublesome; a stimulating plaster, six inches square, was therefore applied to the chest, and a mixture of squills was ordered. She was under treatment seven weeks, and then discharged cured.

Mary P-, married, had suffered from bronchitis for several years. She applied to the hospital with aphonia and with a constant cough. With the laryngoscope the true cords were seen to be of a pink colour, but the rest of the larynx was of a deep congestive hue. The true cords were not readily approximated during articulation, but the false cords fell together. Squill mixture was ordered for the cough, and a solution of nitrate of silver was applied to the interior of the larynx. Each local application was immediately followed by a temporary improvement of the voice. The patient remained under treatment for four months, during which time blisters were applied, inhalations of tincture of iodine and of creasote were used, and solutions of nitrate of silver, chloride of zinc, and muriate of iron were locally applied, all with a marked temporary relief, but with a rapid recurrence of the symptoms. The patjent now left London for Dover, at which place she remained for three weeks. On her return, she stated that her voice had been more distinct whilst away from London, but that it was now as bad as it had been hitherto. A strengthening plaster was now ordered, to cover the whole chest; and the patient was made to respire a spray of the chloride of zinc solution. Finally, galvanism was resorted to. After the galvanism there was no immediate improvement, but on the following day the voice was considerably stronger. Within a few days after the second application of the galvanism the voice had returned to its normal character. This patient, who still suffers from bronchitis, and whose voice continues to become indistinct at times, especially in damp weather, yet occasionally visits the hospital.

$$
\text { ( } T \text { o be concluded.) }
$$

\section{HYDRATE OF CHLORAL IN PUERPERAL EPILEPTIC CONVULSIONS.}

\section{BY A. C. CAMPBELL, M.B., L.R.C.S.E.}

THE following case may prove interesting at a time when the effects of chloral in the complications of obstetric practice are being tested.

On Sunday, June 19th, at 4.30 A.M., I was called to attend a Mrs. J-, aged twenty-eight, primipara, at her full time. A midwife had been with her from 8 P.M. the previous night, but labour had not commenced until 1.30 A.M. Along with the first labour pains a very severe epileptic convulsion made its appearance, the paroxysm recurring every half hour, at the commencement of each labour pain, and leaving the patient perfectly unconscious during the intervals.

On examination I found the os uteri dilated to about the size of a sixpence. The convulsions appeared to be more asthenic than sthenic, the patient looking rather exsanguined, with pulse weak and irregular; face, hands, and legs cedematous, and urine slightly albuminous.

I at once ordered a few leeches to be applied to the temples, but without having the slightest effect.

At 5.30 A.nr., the convulsions still continuing at the same regular intervals, I gave her the following draught:-Forty grains of hydrate of chloral; one drachm and a half of tincture of oranges; two drachms of syrup; water to an ounce and a balf. No return of the convulsions. Pains increased both in strength and frequencr, and she remained insensible and quiet, only being slightly aroused by the pains.

At 8.30 A.Mr. a child was still-born, it having from all appearances been dead for some days.

9.30 A.m.: Left her sleeping soundly, having no knowledge of a child having been born.

5 P.M.: I was asked again to visit her, the convulsions having recurred with more or less severity about every fifteen minutes, along with the after-pains, since 11.30 A.M., or about three hours after the child was born. Thirty grains of chloral having been administered, she was asleep within twenty minutes.

20 th.-11.30 A.м.: Slept well all night; no return of convulsions. Complains of severe headache, but is quite sensible. This was the first time she had appeared conscious since labour had commenced. Slight œdema of face and legs. No albumen in urine. Ordered an ounce of castoroil.

21st.-No return of convulsions. Complains of very severe headache. Ordered a blister to be applied to the temple.

22nd.-Feadache relieved; had a good night; codema disappeared.

She made a good recovery.

Dundee, July 12th, 1870.

\section{A a divtror}

OF THE PRACTICE OF

\section{MEDICINE AND SURGERY IN THE}

\section{HOSPITALS OF LONDON.}

Nulla autem est alia pro certo noscendi via, nisi quamplurimas et morborum et dissectionum historias, tum aliorum, tum proprias collectas habere, et

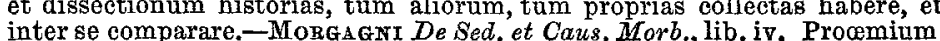

\section{UNIVERSITY COLLEGE HOSPITAL.}

(Skin Department.)

\section{CLINICAL REMARKS ON PRURIGO.}

(By Dr. Tilmory Fox.)

In the course of one of his usual Friday demonstrations, Dr. Tilbury Fox remarked:- "A good deal that is unclinical has been written of late about prurigo, and I am anxious that you should be on your guard about it. You must make a clear distinction between 'prurigo,' phtheiriasis or lousiness, and what is termed a 'pruriginons eruption.' The term 'prurigo,' as generally and loosely used in England, includes these several but very distinct conditions. Now any pimple that has been scratched, and which is covered at its apex with a dark scale formed by dried blood, is said to be 'pruriginous.' Pimples that become pruriginous are not of one kind only, but (and this is certainly lost sight of, it seems to me) of different kinds: for instance, erected and congested follicles, papules formed by deposit of $1 \mathrm{ymph}$ (lichen), papules formed out of wheals, \&c.-any pimple, in fact, when scratched, may become pruriginous; hence we have pruriginous eczema and the like, the erected and congested follicles resulting from the inflammation and lasting congestion being altered by scratching so as to resemble 
those of prurigo. In true prurigo the characteristic feature is the development of solid papules, due to deposit of lymph in the skin, and accompanied by severe irritation of varying kind. These papules are primary; they are not caused by pediculi, but they are altered by scratching so as to present the aspect of 'pruriginous' papules; and, as a part consequence of scratching, other 'pruriginous' papules, originating in erected and congested follicles, are present. In the case of 'phtheiriasis' due to pediculi, the primary pathognomonic lesion is a minute hæmorrhage, not a papule. There seems to be great ignorance as to the anatomy of the pediculus. It is thought to possess jaws, and to bite freely; and certain of the wounds seen on the skin are regarded as having been produced by the bites of the pediculus. This is all a mistake. Prof. Schjödte has clearly shown that the pediculus is furnished with a peculiar sucking apparatus. The mouth is furnished with a labium, capable of being retracted into the upper part of the head. This lip is first inserted into a sweat-pore, and is then protruded. A row of hooks then hold to the parts around, and two pairs of setre are next protruded and applied together so as to form a tube. When the pediculus is sucking, soon a red speck is seen at the top of the head, which exhibits dilatation and contraction; and this red coloration is traced presently into and along the osophagus and the intestines, which latter are seen to be in lively peristaltic action. The effect of the attack of the pediculus is to cause a little escape of blood into the follicle; and it appears as a minute and, at first, bright red speck, the size of a couple of pin pointsnot raised, not itchy, and not removable by pressure. Occasionally some swelling takes place; but this quickly subsides. This lesion differs altogether from a scratched follicle; and I regard it as quite characteristic of the attack of the pediculus. This is Schjötde's representation of the mouth of the pediculus. (See figure.) I have often shown

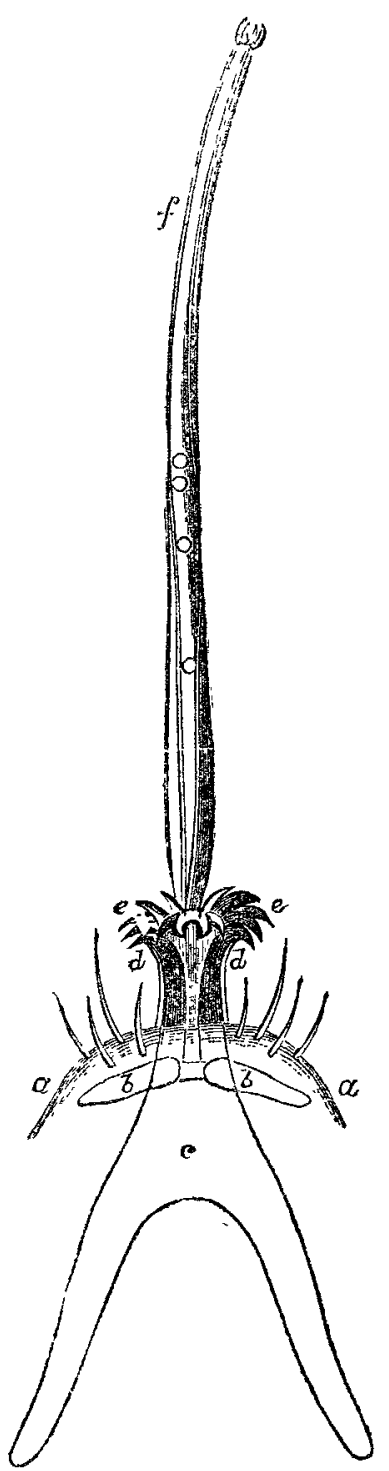

$a$, The top of the head.

$b$, Bands of chitine to give strength.

$\epsilon$, The hind part of the lower lip.

$d$, The protruding part of the lower lip or haustellum.

$e$, The hooks.

$f$, The suction-tube, formed by the apposition of the representatives of the jaws.

A few blood-globules are seen.

to you the hæmorrhagic speck induced by the louse, and you will see it very plainly in the patients now before you. But there are accidental features in phtheiriasis; and these result entirely from the scratching to relieve the irritation set up-scratched congested follicles and papules, urticaria, ecthymatous pustules, \&c. The same are seen in scabies, superadded, as the result of scratching, to the essential features of the disease-viz., the acarus in its cuniculus.

"If it be asked, then, what does the pediculus do, I reply, prefer uncleanly and ill-nourished surfaces; injure the skin by projecting its haustellum into the follicles, and drawing a way blood, leaving behind a minute hæmorrhage, and then sets up irritation, and gives rise, through the scratching practised to relieve the latter, to urticaria, eczema, ecthyma, congested and erected follicles. These latter are the common results of scratching under varied circumstances. Always recollect this fact. The production of minute traumatic hæmorrhagie specks, not the result of any alteration in pre-existing papules or excoriations, and not dependent upon scratching, is the essential and peculiar effect of the attack of pediculi; the pathognomonic sign of phtheiriasis. Hebra and I agree that true prurigo is quite distinct from phtheiriasis, and has nought to do with pediculi. We have had ample evidence of this during the last three months. And now let us go to the cases present to illustrate these several points."

\section{ST. GEORGE'S HOSPITAL.}

\section{HIGH TEMPERATURE IN TWO FATAL CASES OF ACUTE} RHEUMATISM.

(Under the care of Dr. Barchay.)

For the following notes we are indebted to Dr. Cavafy, medical registrar to the hospital :-

Mary D-, aged twenty-three, was admitted into St. George's Hospital on June 10th, suffering from a moderately severe attack of acute rheumatism. There was quick cardiac action, but no abnormal sound or precordial pain. She went on favourably for the first two days after her admission, but on June 13th, at about 6 P.x., she complained quite suddenly of acute pain in the head, and an hour later became delirious and noisy, and rapidly sank. Death occurred soon after nine o'clock, three hours from the first appearance of head symptoms. Half an hour after death the temperature of the body was found to be $110^{\circ} \mathrm{F}$., and next morning, about twelve hours later, as high as $94^{\circ}$. The weather at the time was extremely hot.

At the post-mortem, which was made by Dr. Whipham, seventeen hours after death, the heart was found uncontracted, and contained a small decolorised clot in the right ventricle; the other cavities were empty. On the anterior surface of the heart the visceral pericardium was found spotted with numerous minute ecchymoses. The structure of the heart was soft, and the microscope showed slight fatty granulation in some of the fibres. There were a few ecch rmotic patches at the cardiac end of the stomach. The blood was very fluid, and the brain and membranes quite normal in appearance.

A similar case may be here alluded to shortly, of which full details will be published later. Ellen E-C, aged twenty-four, was admitted, under Dr. Ogle, with her third attack of acute rheumatism, on June 15th. She went on well till the 19th, when she was rather suddenly seized with dyspnoa and vomiting. The vomiting became almost incessant, and she sank and died next day. A short time before death the temperature was $110.8^{\circ}$.

The posi-mortem showed only an uncontracted, empty heart, fluid blood, and a diffluent spleen. No ecchymoses were found.

\section{“DREADNOUGHT" HOSPITAL.}

FUNGOUS DISEASE OF THE TESTICLE, ASSOCIATED WITH DEPOSITS OF ENCEPHALOID CANCER IN THE LIVER; SUDDEN DEATH.

(Under the care of $\mathrm{Mr}$. Rooke.)

THE following case presents many points of great interest in the progress and extensive ulceration of the scrotal tumour, the rapid advance of the hepatic disease after evolution, the absence of jaundice notwithstanding the amount of cancerous deposit in the liver, the sudden death of the patient, and the healthy condition of the lymphatic glands. 